\title{
Hacia una categorización del poder mediático: poder representativo, meta-poder y anti-poder
}

\section{Towards a Categorization of Media Power: Representation Power, Meta-power and Anti- power}

\author{
Ximena González Broquen ${ }^{(*)}$ \\ Instituto de Investigaciones Científicas - Venezuela \\ xgonzale@ivic.gob.ve
}

\begin{abstract}
Resumen
El artículo propone una categorización de lo mediático, articulada a partir la identificación de tres niveles superpuestos de acción del mismo (como poder representativo, como meta-poder, y como antipoder), con la finalidad de mostrar cómo la configuración actual del espacio mediático globalizado desemboca en fin de cuentas en la lenta corrosión de eso que hace la esencia de la democracia: la dimensión pública de lo político.
\end{abstract}

Palabras clave: poder mediático, estética, opinión pública, espacio público, transformación de lo político.

\begin{abstract}
The aim of this article is to propose a categorization of the media, structured from the identification of three overlapping action levels (as representation power, as meta-power, and as anti-power). The aim is to show how the current configuration of globalized media space culminates in a slow corrosion of the very essence of democracy: the public dimension of politics.
\end{abstract}

Keywords: media power, aesthetics, public opinion, public space, transformation of politics.

Mediaciones Sociales, № 8, I semestre 2011, pp. 47-68. ISSN electrónico: 1989-0494. DOI: 10.5209/rev_MESO.2011.n8.3 


\section{INTRODUCCIÓN}

El siglo XXI es el siglo por excelencia de la expansión global del poder mediático, el cual reconfigura un espacio público mundializado, trastornando así diferentes ámbitos medulares de lo político, tales como la representación o la comunicación política. La construcción de una filosofía política del poder mediático, es decir, de una reflexión crítica sobre las implicaciones del poder de los medios en el funcionamiento actual de lo político, que permita abstraerse del ruido y del furor del instante mediático, resulta así necesaria si nos queremos separar de la falta de reflexividad que impone, en ocasiones, ese poder mediático.

Este artículo trata de dar un primer paso en la construcción de esa filosofía política persiguiendo dos objetivos concretos: primero, proponer una categorización del poder mediático, lo que consiste en clasificar, por niveles diferenciados, los ámbitos y las formas en que se ejerce ese poder. Y segundo, apoyarnos en esa categorización para analizar el papel de ese poder en las transformaciones que está sufriendo actualmente lo político. A este respecto entendemos que los medios han venido asumiendo poco a poco un conjunto de funciones relacionadas con el ámbito de lo político, habiéndolo transformando radicalmente.

Antes de comenzar, es importante delimitar nuestro marco conceptual en cuanto a la definición de poder mediático que usaremos aquí: no se trata de pensar el poder de los medios como poder sobre, es decir únicamente como poder de coerción, sino de alejarse, a través de la categorización propuesta, de los estudios que le dan o demasiado poder-como los estudios que hacen de los medios instrumentos de manipulación ${ }^{1-}$, o muy poco poder -como los estudios que subrayan la distancia crítica de los individuos frente a los mensajes mediáticos, como los estudios de la recepción o los estudios culturales²-.

1 Existe una larga tradición de pensamiento que ve los medios como instrumentos de propaganda y/o de manipulación, que va desde Tchakhotine (1939), pasando por diversos análisis realizados sobre regímenes totalitarios (ver Domenach [1950] 1973) sobre el poder de la publicidad (ver Packhard [1957] 1959) hasta los análisis de la escuela de Francfort y sus seguidores sobre la industria cultural y la alineación (ver Adorno y Horkheimer [1947] 1998), o más recientemente Marcuse ([1954] 1993).

2 Ver por ejemplo análisis precursores de Tarde ([1989] 1999), la teoría del Two step flor desarrollados por Lazarsfeld, Berelson, y Gaudet (1944) y Lazarsfeld y Katz (1955), la teoría de los "usos y gratificaciones" desarrollada a por Katz y Liebes (1990), la teoría de la "codificación/decodificación" desarrollada por Hall (1973), así como más recientemente, los análisis

Mediaciones Sociales, № 8, I semestre 2011, pp. 47-68. ISSN electrónico: 1989-0494. DOI: 10.5209/rev_MESO.2011.n8.3 
Como alternativa a estos dos extremos, entendemos que los medios participan del poder ${ }^{3}$ como elementos que transforman, no solamente la manera de hacer y pensar la política, sino lo político en cuanto tal. Es decir, que entendemos ese poder no como poder autónomo o agregado al sistema de poderes clásicos que definen los sistemas democráticos, ni tampoco como un poder al servicio de otro poder (poder económico por ejemplo), sino como elemento intrínsecamente político.

El artículo está dividido en los tres niveles de acción en que hemos clasificado el poder mediático global, siguiendo la sistematización propuesta por el filósofo francés Marcel Gauchet: poder representativo, contra y meta-poder y anti-poder. Tras ese análisis de los tres niveles discutiremos en las conclusiones cómo la configuración de un espacio mediático mundializado desemboca, a fin de cuentas, en la lenta corrosión, es decir destrucción, de eso que constituye la esencia de la democracia: la dimensión pública de lo político.

\section{NIVEL 1. MEDIOS-MEDIADORES: PODER REPRESENTATIVO}

La naturaleza primera de los medios es de ser mediadores, es decir, de ser instrumentos que sirven de intermediarios para la transmisión masiva y rápida de informaciones (en un sentido amplio). Desde la impresión de los diarios, pasando por el telégrafo, el teléfono, la televisión, la radio, la computadora y la red, la función de los medios siempre ha sido la de difundir información, estableciendo contacto entre un número creciente de personas más o menos lejanas en el espacio-tiempo.

Los medios pueden ser entonces definidos en primera instancia como "instrumentos para difundir", por lo que su principal ámbito de acción puede decirse que es el de la representación. En este primer nivel, el poder de los medios-mediadores se define como poder representativo de mediación.

paradigmáticos de Wolton $(1992,1998)$ o de Castells (2010) sobre las nuevas alternativas que ofrecen las redes de Internet a la manipulación de los medios tradicionales.

3 Clastres $(1973,1981)$ critica justamente el impensado de la filosofía política occidental que desemboca en la reducción de la noción de poder a la relación de comando-obediencia, es decir a la coerción. Siguiendo este autor planteamos aquí una comprensión de la noción de poder, inmanente a lo social, como lugar (y no como relación de dominación) de organización de la vida colectiva, lugar de reflexión práctica de la colectividad sobre su propio modo de existencia.

\footnotetext{
Mediaciones Sociales, № 8, I semestre 2011, pp. 47-68. ISSN electrónico: 1989-0494. DOI: 10.5209/rev_MESO.2011.n8.3
} 
Los medios son instrumentos que, para difundir información, la representan, es decir, la ponen en escena, la escenifican.

En la multitud de informaciones, de ideas, de imágenes, de datos, etc., que los medios difunden representándolos, podemos identificar, desde el punto de vista particular de nuestro estudio, dos ejes principales: la mediación-representación de lo político, y la mediación-representación de la sociedad y de sus ciudadanos. Es decir, que a través de los medios lo que se da es la mediación de lo colectivo.

\subsection{Representación de lo político: conexión e información, versus participación y acción}

Lo primero que podemos destacar es que los medios constituyen una pieza necesaria del proceso representativo, proceso central de las democracias contemporáneas. Los medios son los instrumentos principales que permiten a los individuos tener acceso a la esfera de lo político a través la representación de la política que éstos ofrecen. A su vez son los instrumentos que permiten a la esfera política ponerse en escena y, de esta manera, entrar en contacto con los individuos. El modelo político de democracia representativa necesita la escena mediática para poder ejercerse. Sin esta escena, la política y más allá de ella, lo político, tal como está estructurado hoy en día, no pueden funcionar.

Si los medios participan de este modo de lo político ${ }^{4}$, hay que preguntarse entonces hasta qué punto y cómo permiten acceder a esa esfera política, es decir, qué grado de participación propician en el funcionamiento político de nuestras sociedades.

Los medios permiten a los individuos participar ficticiamente en la política, sin que tengan necesariamente que actuar o comprometerse en ella. Por ejemplo, siguiendo los grandes debates televisivos e informándose de los gestos y hechos de los principales actores de la vida política, el individuo tiene acceso a esa esfera con independencia de que participe o no, de forma efectiva en la vida política, militando o formando parte de alguna organización social o política. De una misma manera, siguiendo "en directo” una manifestación, el individuo participa virtualmente de ésta, sin tener

4 Para una reseña histórico-conceptual ver Castells $(1996,1997,1998)$.

Mediaciones Sociales, № 8, I semestre 2011, pp. 47-68. ISSN electrónico: 1989-0494. DOI: 10.5209/rev_MESO.2011.n8.3 
que salir a la calle, sin tener que comprometerse en la realidad factual, los medios hacen posible una participación politica virtual.

Lo importante aquí es ver que esta participación virtual no hace de los individuos un pueblo de ciudadanos, sino los miembros regados de un público. Público, por tanto, caracterizado como pasivo que, frente a la noción de pueblo, no influye ni participa realmente sobre y de ese poder político escenificado para él.

La conclusión que podemos extraer de esta realidad es que los medios propician la transformación del pueblo de ciudadanos que interactúan -a través de la construcción de un espacio público- en la construcción de lo político, en un público de espectadores que se conecta ${ }^{5}$, a través de un espacio público mediático, a la esfera política transformada en espectáculo mediático. De este modo, la participación es reemplazada por la conexión y la acción por la información en el marco de una contemplación fascinada y fascinante de la política-espectáculo globalizada e instantánea ${ }^{6}$. El ámbito de lo político se confunde entonces con esa escena mediática en la cual la transmisión de la información pretende tomar el paso sobre el conocimiento directo de la realidad: la conexión se erige en experiencia última y global de la realidad del mundo político. Tal es el nuevo espacio público de participación virtualizada que reconfiguran los medios: un espacio globalizado instantáneo de conectividad espectacular.

\subsection{Representación de la sociedad: identidades de forma versus iden- tidades de contenidos, imagen global de la sociedad como cuadre referencial vacío}

Una de las funciones principales de lo político es la de establecer el lazo de la sociedad a ella misma. El poder de los medios de comunicación se puede analizar como poder para representar la imagen misma de la sociedad. Esa imagen que crean y difunden de la sociedad y de su identidad

5 Gracias a esta conexión permanente, los medios crean la ilusión del mantenimiento de la soberanía popular, es decir, de su participación en la cosa pública y el poder, en los tiempos muertos que existen entre cada elección.

6 Ver estudios sobre las categorías de "evento" y de "directo" y en particular los análisis precursores de Innis (1950, 1951), de McLuhan y Powers ([1989] 1995), y más recientemente de Virilio $(1999,2007)$. 
como ente colectivo termina siendo una imagen meramente estética, formal, basada en criterios antes sentimentales que racionales.

El primer punto a destacar a este respecto es que los medios de comunicación permiten al individuo "conectarse" con su propia sociedad. Conectándose con los medios, el individuo se conecta con toda una serie de imágenes de la sociedad a la cual pertenece, estableciendo un lazo entre su vida privada y lo colectivo ${ }^{7}$. Los medios de comunicación ocupan de esta manera una función central en el sistema general de representación simbólica de la sociedad. La pantalla de televisión puede ser vista como el paradigma de ello, como espejo en el que se reflejan imágenes deformadas de la sociedad, que no son copias fieles de ésta, pero que tampoco constituyen una ilusión en cuanto tal: éstas constituyen una ficción ${ }^{8}$, es decir una narración estética construida mediáticamente de la sociedad. Ficción que, como construcción simbólica, no deja de poseer realidad y efectividad como representación de lo colectivo. Las telenovelas, los informativos, la publicidad, los juegos, los debates sociales o políticos, constituyen un gran "catálogo" de la sociedad en el cual cada género pretende reflejar a su manera la sociedad. Gracias al acceso a esa pluralidad de imágenes distintas e instantáneas, el individuo tiene el sentimiento de estar conectado a la sociedad formándose una imagen global de ésta.

Lo que los medios transmiten de esta manera al individuo es una imagen global de la sociedad pero propagada a partir de una pluralidad de puntos de vista fragmentados. La pregunta que podemos hacernos es ¿qué vehicula esa imagen de la sociedad a la vez global y fragmentada?, nuestra tesis es que produce una pérdida de sentido de lo colectivo: la razón que explica esta tesis es que la pluralidad de imágenes difundidas jamás quedará unificada, evitando que el sujeto relacione unas imágenes con otras y logre captar ese sentido de lo colectivo, de lo social como globalidad.

7 Es importante destacar aquí que, en muchos casos, los medios se convierten en la fuente principal de acceso a ese colectivo. Ver análisis sobre "agenda-setting" de McCombs y Shaw (1972).

8 Las sociedades se estructuran a partir de relatos ficticios que tienen como función representar y actuar -en una palabra dramatizar- el sentido de la sociedad, es decir el sentido del estar juntos. Nuestra tesis es que, de la misma manera que los mitos estructuraban las sociedades (mal) dichas "arcaicas", las ficciones mediáticas estructuran la sociedad en el orden de la representación. 
Por ende, el poder mediático como poder representativo no produce solamente un cierto tipo de imagen-imágenes de la sociedad sino que, a partir de ésta(s), proporciona un nuevo tipo de identidades que podemos definir como identidades estéticas, en el sentido de identidades sentimentales-sensacionales ${ }^{9}$. Es decir, de identidades que se configuran a través del mero pathos del individuo y cuyo contenido guarda relación con valores morales, políticos o sociales sino con una preeminencia del valor estético.

Esto es patente en los modelos ${ }^{10}$ estéticos que transmiten los medios en relación con la belleza, el éxito social, la educación o el comportamiento. Son modelos mediáticos vacíos de todo contenido político y en donde prima lo estético. Modelos que pretenden no imponer nada pero que son reproducidos de manera prácticamente idéntica por los sujetos. Un ejemplo de esto se encuentra en la juventud actual que posee mundialmente los mismos rasgos estéticos (de forma), sea en la manera de vestirse, de hablar, etc.. Con esto no se pretende que todos los jóvenes sean idénticos, sino subrayar el poder de moldear de los medios de comunicación.

Este primer nivel del poder de los medios como poder de representación (ver cuadro resumen), constituye un primer piso en la elaboración de un verdadero poder simbólico de estructuración de las sociedades.

Como acabamos de ver, este primer nivel del poder mediático consiste en un poder de representación que actúa a dos niveles:

Primero, representando una imagen de lo político que dificulta la participación real en la esfera pública y en la toma de decisiones políticas. Los medios permiten la conexión virtual del ciudadano con la vida política, convirtiéndole en espectador pasivo.

Y segundo, representando una imagen de lo social que dificulta la acción del sujeto sobre su entorno. Los medios proyectan una imagen de la

9 Aunque aislamos el factor mediático para poder, justamente, caracterizarlo, la transformación de las identidades responde también a factores sociales, económicos, políticos y culturales que desbordan el cuadro de nuestro análisis.

${ }^{10}$ Estos modelos no pretenden cumplir función de ideal, es decir, servir de cuadros referenciales para la construcción de las identidades, sino ofrecerse a la vista y libre elección de los espectadores; sin embargo, es innegable que modelan, estéticamente, los individuos. Sobre diferencia entre modelo e ideal ver los análisis de Freud $(1982,1984,2006)$. 
sociedad que no permite que el ciudadano adopte una idea crítica del colectivo al que pertenece sino sólo valores estéticos que conforman identidades vacías de todo contenido social y político.

El poder mediático, que estamos categorizando, es por tanto, en primer lugar, un poder para representar cosas y, en esa medida, influir sobre la vida política y la acción social. A continuación veremos que los medios no sólo representan, sino que, en ocasiones se erigen ellos mismos como portavoces de la opinión y voluntad de los ciudadanos actuando como un poder en sí mismo. Es el poder de los medios como opinión pública (o meta-poder) que constituye el segundo nivel de nuestro análisis.

Gráfico 1

Nivel 1: Medios-mediadores y Poder de representación

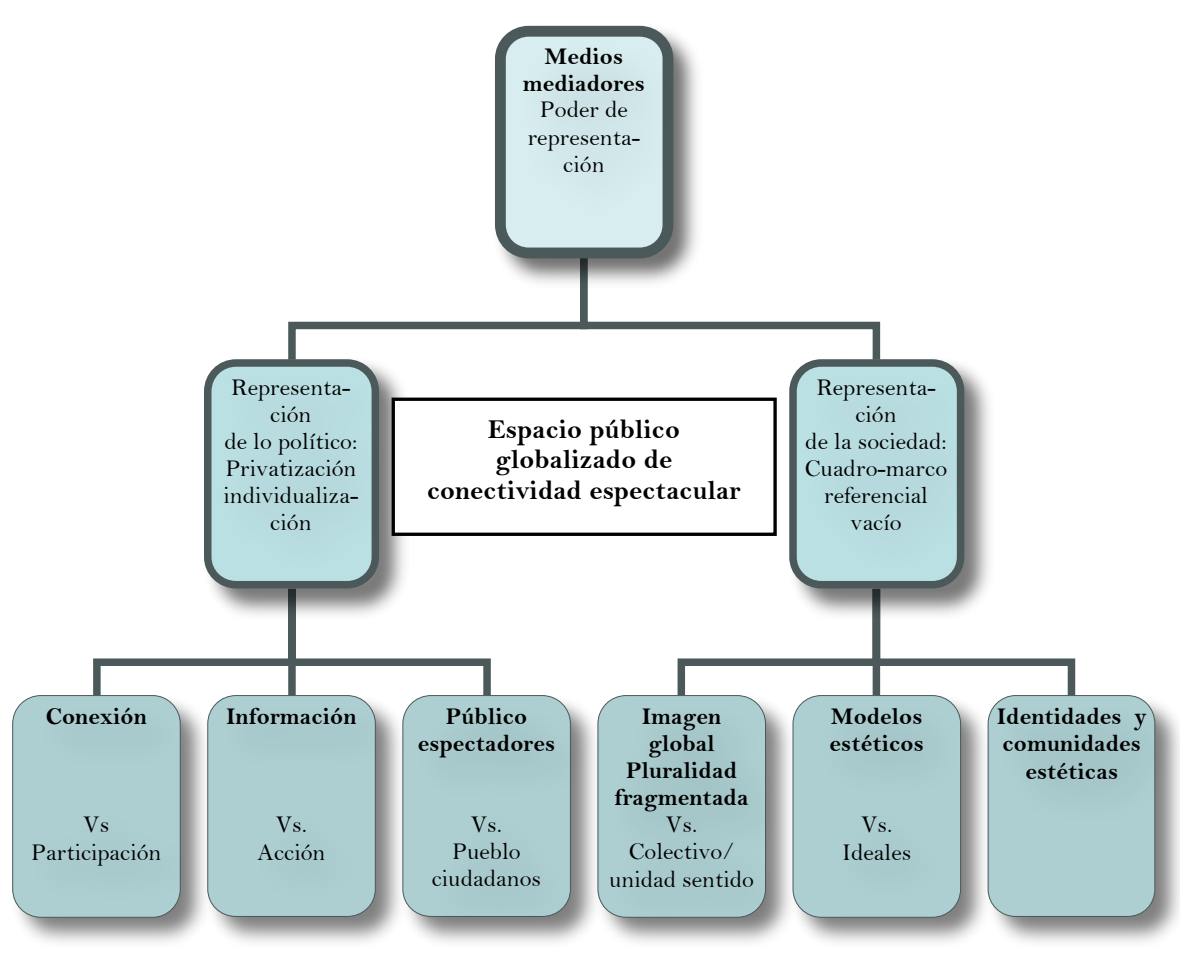

Mediaciones Sociales, № 8, I semestre 2011, pp. 47-68. ISSN electrónico: 1989-0494. DOI: 10.5209/rev_MESO.2011.n8.3 


\section{Nivel 2. MEdios-ACTORES: LOS MEdios COMO META-PODER}

Cuando se habla del poder de los medios, por lo general no se hace referencia a su poder representativo, sino al llamado "cuarto" poder. Es decir, que se hace referencia a la corriente acepción de los medios como medios-actores, dotados de funciones propias e influyendo sobre eso que deberían solamente difundir y representar. Para poder analizar este segundo nivel de poder, nos apoyaremos sobre los análisis desarrollados por Marcel Gauchet a propósito de la ideología de los derechos humanos (Gauchet, 2002) y sobre la caracterización que efectúa de los medios como contrapoder, meta-poder y anti-poder (Gauchet, 2006).

A partir de la influencia creciente de los medios sobre los otros poderes, se fue desarrollando la idea de un poder propio y autónomo de los mismos, es decir la percepción de éstos como "cuarto" poder. El filosofo británico Burke fue quien, en el siglo XVIII, impulsó el uso de esta expresión para describir la influencia de los periodistas durante la Revolución Francesa, quienes actuaban como contrapeso político de los tres poderes clásicamente definidos (el legislativo, el ejecutivo y el judicial). Según esta acepción, la función primera de este "cuarto" poder fue la de limitar los otros poderes, cumpliendo entonces, una función de contra-poder en el desarrollo de la democracia representativa.

¿Cómo se ejerce el contra-poder de los medios? Según Marcel Gauchet, es ejercido a través de la opinión pública ${ }^{11}$. Una figura que ejerce justamente una función de control y de arbitrio al ejercicio de los poderes políticos y que encuentra en el espacio público mediático, tal como lo hemos definido anteriormente, su espacio natural de despliegue ${ }^{12}$.

Cuando los medios, como contra-poder, sirven como espacio para la información y como espacio para la denuncia, la opinión pública puede convertirse en una plataforma de contrapoder. En este caso, esa opinión

\footnotetext{
${ }^{11}$ Marcel Gauchet define la democracia representativa contemporánea como democracia de control, de la cual emergen dos actores fundamentales -anexos al sistema- $\mathrm{y}$, al mismo tiempo: la figura del juez y la figura de la opinión pública. Según nuestra comprensión del tema, estas dos figuras han venido mezclándose y fundiéndose la una en la otra, hasta hacer de la opinión publica la figura misma de un juez supremo.

12 Ver los análisis de Habermas $(1998,1981)$ sobre el papel de la opinión pública en el desarrollo de la democracia y la conformación del espacio público.
} 
pública se proyecta como juicio público del pueblo soberano ${ }^{13}$, a diferencia de las decisiones políticas ejercidas como cuerpo electoral. Los medios pueden, por tanto, como contra-poder ${ }^{14}$, cumplir una labor de balance y reajuste exterior al sistema político, volviéndose necesarios para su buen funcionamiento.

Sin embargo, esta función de contra-poder ha venido modificándose fundamentalmente. En efecto, la figura de la "opinión publica”, cuyo poder va a ir extendiéndose poco a poco, cumple hoy en día, retomando la caracterización de Marcel Gauchet, una función de "meta-poder". Es decir, que la opinión publica se ha transformado en un poder que pretende situarse por encima del poder político (ya no más en un mismo nivel que éste como contrapeso), y que, al mismo tiempo, se define totalmente en función de éste (el objeto central sobre el cual se ejerce la opinión pública es el poder político, por lo cual su existencia está totalmente condicionada a éste). Veamos esto un poco más de cerca.

Hemos visto que el contra-poder es un poder de control que vigila, a través la figura de la opinión pública, las decisiones o acciones de los otros poderes. En cuanto la opinión pública se transforma en meta-poder, se convierte, según la expresión de Marcel Gauchet, en doble simbólico del cuerpo electoral ${ }^{15}$. Podemos agregar, en doble simbólico del pueblo soberano. En efecto, en las democracias representativas, la sociedad elige sus representantes, pero es la opinión pública, verdadera censura mediático-virtual, quien juzga públicamente la esfera política en los tiempos muertos que separan cada cita electoral. De esta manera, la opinión pública se integra al juego democrático, volviéndose parte integrante del sistema.

13 "La información sobre los actos de poder, por una parte, sobre la actualidad a los cuales se vinculan, por otra, tiene esa propiedad remarcable de hacer surgir la figura de un juicio público del pueblo soberano, diferente de su decisión política, pero suficientemente ligada a ella para oponer una barrera eficaz a cualquier poder" (traducción propia) (Gauchet, 2006: 21).

14 "Hay contra poder en la medida en que la transmisión de legitimidad de los representados a los representantes no es total, y cuando el poder está obligado a legitimarse cotidianamente" (traducción propia) (Gauchet, 2006: 22).

15 "Este es el significado más profundo del fenómeno de la opinión, en nuestros regímenes, que por más intangible que sea, constituye una de sus piezas clave, como doble símbolo del cuerpo electoral, durante los intervalos del sufragio, y antes el cual ningún gobierno puede eludir la obligación de rendir cuentas" (traducción propia) (Gauchet, 2006: 21). 
La pregunta que debemos hacernos es la siguiente: ¿cómo se ejerce ese meta-poder? Podemos resaltar que, si se trata de juzgar, estamos aquí en el campo de lo moral, es decir, en el campo de lo que sustenta los juicios de valores. Es decir que este meta-poder se fundamenta simbólicamente en el orden de lo moral. ¿Y cuál es la fundación moral de este meta-poder de la opinión público-mediática?

Marcel Gauchet identifica de manera rotunda la fundación moral de este meta-poder de la opinión pública en las críticas que hace a lo que llama la "sacralización” de los derechos humanos ${ }^{16}$, a través de la cual estos últimos no son ya únicamente el principio último de legitimidad y de fundamento del derecho, sino que se convierten también en el basamento moral de la opinión público-mediática ${ }^{17}$. Derechos humanos que funcionan entonces como verdadera ideología ${ }^{18}$, es decir, como base simbólica que fundamenta y explica el sistema de representación moral y político de las sociedades occidentales ${ }^{19}$.

En este segundo nivel (ver cuadro resumen) vemos en obra lo que constituye el nervio de la transformación de los medios en verdaderos actores del sistema político (y no ya solamente como representación de) a través de la emergencia del papel de la opinión público-mediática, doble

16 "Todo aquello que los medios de comunicación necesitan -lo concreto de las situaciones, la simplicidad de los mensajes, el carácter consensual de los valores- es suplido en abundancia por la política en nombre de los derechos. Esa política le aporta la imagen choc, a la escena conmovedora, el testimonio identificador, la evidencia irrecusable de los criterios sobre los que pronunciarse, la superación de las oposiciones y la reunión de los corazones alrededor de certidumbres últimas sobre el bien y el mal" (Gauchet, 2004: 270).

${ }^{17}$ Para citar un ejemplo, CNN en español ha arremetido en reiteradas ocasiones contra el estado Venezolano, denunciando una supuesta "dictadura" y violación de derechos humanos, sin presentar datos o cifras fidedignas al respecto, colocándose en nombre del "sacro-santo" respeto a los derechos humanos, como sujeto de una opinión pública supra-nacional.

${ }^{18}$ Los Derechos Humanos han venido efectivamente ocupando un lugar muy particular como ideología, es decir, no sólo como principio de legitimidad universal, sino también, como visión del mundo social y sobre el fundamento de la acción pública. "Fundamentos, es decir no simplemente la posición de valores reguladores supremos hacia los cuales tender tan bien como mal; no simplemente el alcance de barreras infranqueables a oponer a los poderes, sino la posición y el alcance de principios de definición, a la vez primeros y exhaustivos, reclamando volver a tomar todo desde la base y no dejando escapar nada" (Gauchet, 2004: 250).

${ }^{19}$ Como muestra de esto, las últimas guerras desatadas por los EEUU o la ONU en el medio Oriente (Afganistán, Irak, Libia), que se justifican en nombre de la defensa e implementación de derechos humanos para pueblos que son masacrados bajo tales justificaciones. Ver análisis, de Charon y Mercier et al. (2004) sobre el papel de los medios en la guerra de Irak.

Mediaciones Sociales, № 8, I semestre 2011, pp. 47-68. ISSN electrónico: 1989-0494. DOI: 10.5209/rev_MESO.2011.n8.3 
simbólico del pueblo soberano. Vamos a ver ahora, en un tercer nivel, cómo este papel de la opinión público-mediática en lo político se transforma en poder de destrucción de lo político, pretendiendo tomar su lugar.

Gráfico 2

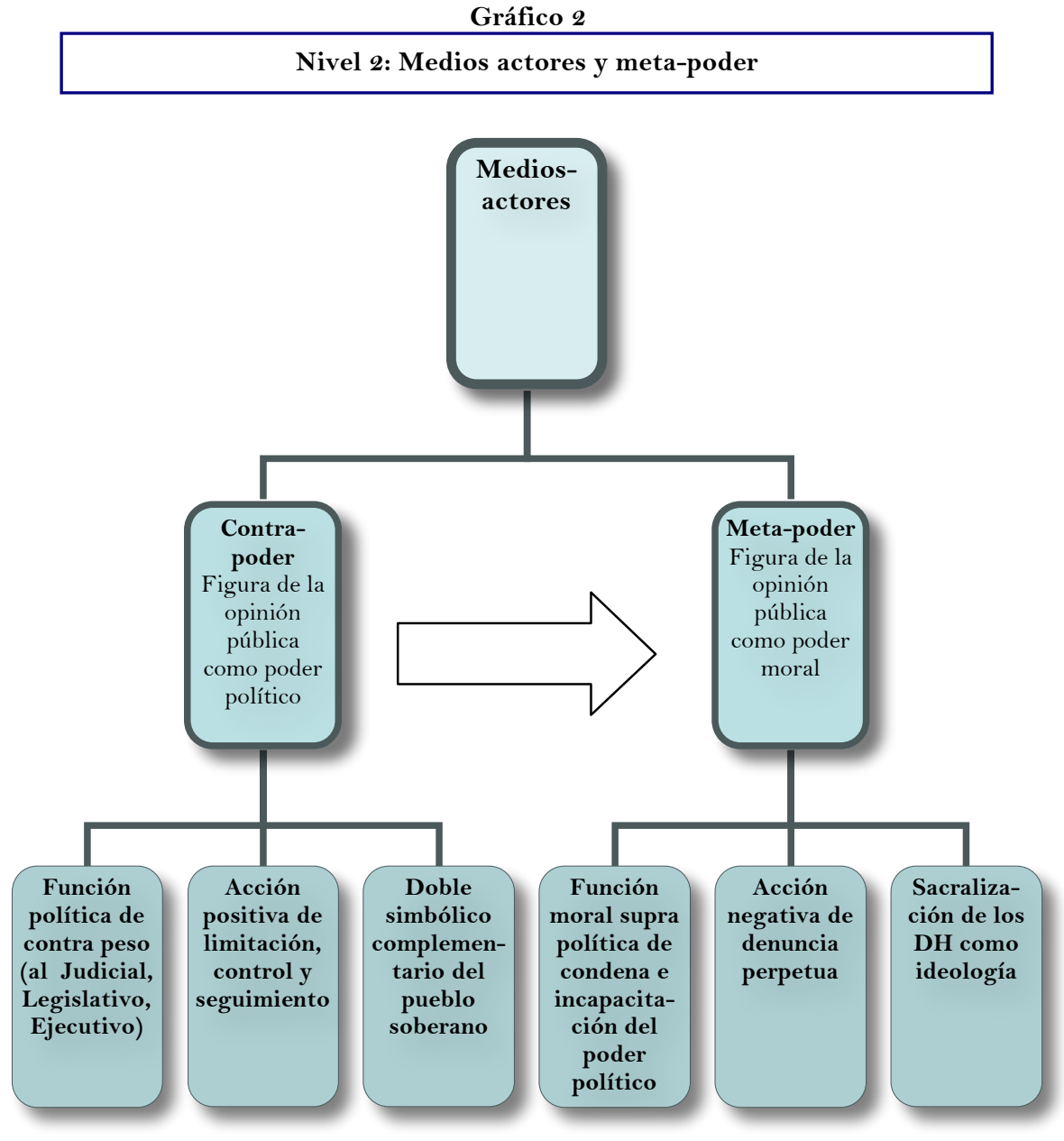

Mediaciones Sociales, № 8, I semestre 2011, pp. 47-68. ISSN electrónico: 1989-0494. DOI: 10.5209/rev_MESO.2011.n8.3 


\section{NiVEL 3. LA OPINIÓN PÚBLICO-MEDIÁTICA COMO ANTI-PODER}

Hemos visto que en nombre de los derechos humanos la opinión público-mediática tiene validez moral para emitir su juicio. Vamos a ver cómo esta opinión, a través de la denuncia y la descalificación en contra de los poderes políticos, se transforma en un verdadero anti-poder, es decir en poder de destrucción y de deslegitimación de lo político ${ }^{20}$.

Las funciones de contrapeso de los medios (contra-poder), en un primer momento positiva y necesaria al sistema democrático, así como de doble simbólico y juez (meta-poder), han tomado en la actualidad una forma negativa y destructora. La opinión público-mediática, doble simbólico del cuerpo electoral, ya no pretende únicamente situarse por encima de él, sino sustituirle en nombre de un fundamento supuestamente supra-moral (los derechos humanos). De esta forma, se vuelca de manera destructiva contra las decisiones tomadas por el cuerpo electoral a través de sus representantes, es decir, se vuelca contra la voluntad del pueblo soberano.

En cuanto esta opinión público-mediática se erige, ya no más únicamente como portavoz, sino como el agente de salvaguardia de los derechos humanos, recae sobre ella y sobre todas sus acciones, la aureola moral universalista que estos derechos poseen. Aureola moral que la posiciona, no solamente por encima de los poderes políticos que son entonces percibidos como inferiores a ella, sino como adversario a éstos. De doble simbólico del pueblo soberano, la opinión público-mediática se transforma en verdadero opositor y contrincante del mismo ${ }^{21}$.

Esta opinión público-mediática legitima así sus acciones destructivas en nombre de su cruzada moral universalista de defensa de los derechos humanos (libre expresión, etc.) que la coloca moralmente por encima y más allá de toda ley. Esta sacralización mediática de los derechos humanos sitúa

\footnotetext{
${ }^{20}$ La idea de que los medios participan de la destrucción de lo político ha sido analizada como algo negativo -ver Martín-Barbero (1998) y de Baudrillard (1976,1981)- así como de manera positiva por la corriente postmoderna, quienes celebran así la destrucción de lo político -ver Maffesoli (2005)-.

${ }^{21}$ Ver por ejemplo el papel jugado por los medios de comunicación en el golpe de Estado al presidente Allende en 1973 (analizado por Mattelart), así como en el golpe de Estado perpetrado contra el presidente Chávez en Venezuela en 2002 (analizado por Britto García, 2008).
} 
así la opinión público-mediática más allá y por encima del juego democrático, más allá y por encima del pueblo soberano.

De una tal manera ésta se convierte en meta-voluntad general, destruyendo y deslegitimando hasta la existencia de lo político. Los medios ya no son más mediadores entre la sociedad y la política, sino que absorben en sí estas dos categorías, pretendiendo actuar a la vez como sociedad (opinión pública) y como juez político (soberanía de los derechos humanos), obviando la necesaria mediación de los poderes democráticos22. La opinión públicomediática pretende así tener el poder moral de arremeter contra todo poder legítimo y democrático ${ }^{23}$.

Opinión público-mediática que absorbe las funciones y características del pueblo soberano, con el fin de ir tomando poco a poco su lugar, destruyendo y deslegitimando los mecanismos de participación y de representación, en nombre de su meta legitimidad moral. Es decir, que la sacralización del poder moral de la opinión público-mediática destruye poco a poco el poder democrático, pretendiendo sustituirse a él. El poder mediático pretende ser a la vez el soberano y la expresión del soberano: representar y actuar en un mismo gesto (ver cuadro resumen).

A fin de cuentas, este poder mediático, que a través de la dogmatización moral de la opinión público-mediática, reduce la participación política a la conexión-información, la comunidad a su dimensión emotivosentimentalista, el espacio público al espacio privado, el ciudadano al espectador y el votante a denunciante, tiene como consecuencia la descalificación y destrucción de lo político en cuanto proyecto democrático de sociedad.

${ }^{22}$ En este orden de idea, sería muy interesante analizar cómo los medios presentan las "revoluciones Facebook" del medio oriente (Túnez y Egipto, 2011) induciendo la idea de que las redes sociales de la WEB constituyen los voceros y representantes legítimos de los pueblos soberanos, y por ende los verdaderos actores políticos.

${ }^{23}$ Por ejemplo la SIP (Sociedad Interamericana de Prensa) se erige como organismo supra nacional, y asume la potestad de sancionar, al menos moralmente, a los gobiernos de países que intentan regular el rol de los medios de comunicación (como Venezuela, Ecuador o Bolivia), acusándolos de dictatoriales e autoritarios. Es muy interesante notar que la SIP no es otra cosa que la asociación de dueños de grandes emporios mediáticos en América, y que sus pronunciamientos, en la mayoría de los casos, se basan en la libertad de expresión como derecho humano, situada según ellos mas allá y por encima de todo poder político que pretenda regularla. 
El modelo de sociedad que promueve entonces esta opinión públicomediática es un modelo de sociedad en el cual la organización de lo colectivo pretende regularse por y dentro del espacio mediático de la opinión pública. Si el primer paso es la destrucción de la dimensión política del sistema democrático, el segundo, es sin lugar a duda la destrucción del soberano en cuanto tal, es decir del pueblo.

Gráfico 3

Nivel 3: La opinión público-mediática como anti-poder

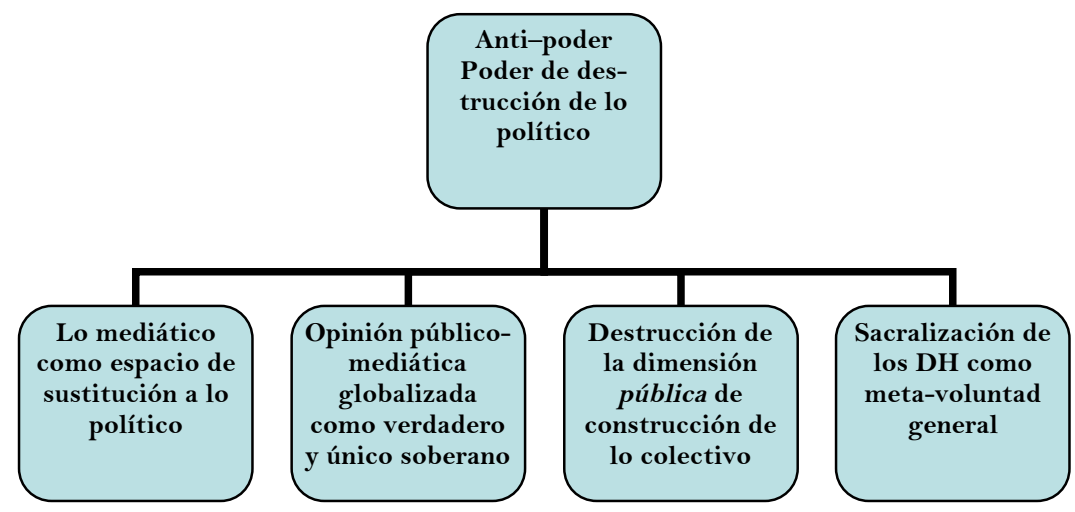

\section{Conclusión}

A través la categorización de estos tres niveles de lo mediático, como poder representativo, como meta-poder y como anti-poder, hemos tratado de analizar uno de los ejes fundamentales de las transformaciones profundas de los sistemas de producción simbólicos que están viviendo las sociedades contemporáneas mundializadas. En efecto, el ámbito de lo mediático ha venido ocupando espacios que hasta hace poco eran del orden de lo político en cuanto tal, sustituyendo a éste en muchos casos, y convirtiéndose en uno de los escenarios primordiales de fábrica, al nivel político de lo simbólico, de las sociedades.

El ámbito de lo mediático está dominado por dos dimensiones, a priori contradictorias, pero en realidad complementarias. Por una parte, por la

\footnotetext{
Mediaciones Sociales, № 8, I semestre 2011, pp. 47-68. ISSN electrónico: 1989-0494. DOI: 10.5209/rev_MESO.2011.n8.3
} 
preponderancia del carácter individual y estético-sentimental del espacio de lo público, es decir del espacio de lo común, tal como lo hemos analizado en el nivel 1. El tipo de colectivo que desdibuja el espacio mediático, que hemos analizado a la vez como cuadro vacío y como fragmentación, plantea la necesidad de un cuestionamiento crítico sobre la función representativa del poder mediático como poder político de producción de lo común. En lazo con este tema, el advenimiento de la opinión públicomediática como avatar del soberano, que hemos caracterizado tanto en el nivel 2 , desarticula en parte, y absorbe en si las funciones políticas de acción y participación de lo colectivo, tal como lo hemos señalado en el nivel 3.

En estas dos dimensiones lo que vemos a la obra es la reducción de lo colectivo a dimensiones privadas, individuales y de mera forma, así como la destrucción de la dimensión pública de lo político, es decir la destrucción de la dimensión colectiva pública de construcción voluntaria de lo político.

La pregunta que podemos hacernos concierne entonces a la capacidad que tenemos de controlar y dirigir este sistema mundializado de producción simbólica, que toca a la esencia de lo que hace lo común. La globalización, fundamentalmente económica, no sólo es preocupante en este nivel, sino al nivel más general, de lo que autores como Pierre Legendre llaman "la fábrica" de los individuos. ¿Qué tipo de sociedad, qué tipo de individuos y qué tipo de "común" este sistema mediático-mundializado de producción simbólica configura?

Para poder construir respuesta alguna a estos interrogantes, resulta importante salir de la disyuntiva que radica en celebrar, como lo hace la corriente post moderna, el advenimiento del "fin" de lo político y el reino de la sociedad mediática del goce estético, o al contrario, en condenar rotundamente lo mediático y las TIC, llamando nostálgicamente al retorno de las formas tradicionales de organización política.

La conclusión a las cual nuestra reflexión no lleva radica entonces en la importancia de reflexionar sobre la primacía del rol que lo mediático juega en la producción simbólica, y como tal política, de la sociedad. Sabiendo que no se trata de pensar lo mediático como el único ámbito de producción simbólica de las sociedades, sino de reconocer su carácter fundamental para poder, a partir de ahí, plantearse qué tipo de mundo se está construyendo a través de él. 
Solamente tomando conciencia de la importancia del ámbito de lo mediático y de su preponderancia en la construcción simbólica de nuestras sociedades podremos en un segundo momento reflexionar sobre cómo rearticular un tal ámbito de manera que podamos hacer de este no el destructor de lo político, sino parte positiva de él.

Si reconocemos el papel fundamental que el espacio de lo mediático juega en la fábrica de los individuos y de la sociedades contemporáneas, es decir si reconocemos lo mediático como intrínsecamente político, quizás podremos reapropiarnos de este espacio, y re-inventarlo. Quizás.

\section{Bibliografía}

Anderson, B. (1993): Comunidades imaginadas. México: Fondo de Cultura Económica.

Adorno, T. Y Horkheimer, M. [1947] (1998): Dialéctica de la Ilustración. Fragmentos filosóficos. Madrid: Trotta.

BaUdrillard, J. (1976): A l'ombre des majorites silencieuses ou la fin du social . París: Utopie.

BAUdrillard, J. (1981): Simulacres et simulations. París: Galilee.

Britto García, L. (2008): Dictadura Mediática en Venezuela: Investigación de unos medios por encima de toda sospecha. Caracas: MINCI.

Castells, M. (1996): La Era de la Información. La Sociedad Red. Madrid: Alianza.

Castells, M. (1997): La Era de la Información. El poder de la identidad. Madrid: Alianza.

Castells, M. (1998): La Era de la Información. Fin de Milenio. Madrid: Alianza.

Castells, M. (2010): Comunicación y poder. Madrid: Alianza.

Champagne, P. (1990): Faire l'opinion. Le nouveau jeu politique. París: Minuit. 
Charaudeau, P. (2005): “¿Nos manipulan los medios?”, Cuadernos de Información y Comunicación, $\mathrm{n}^{\circ}$ 10, pp. 319-330.

Charon, J.M. y Mercier, A. (2004): Armes de communication massive. París: CNRS.

Chomsky, N. (2002): La Propaganda y la opinión pública. Barcelona: Crítica.

Chomsky, N. (2007): "El control de los medios de comunicación”, Red Voltaire, 7 de marzo de 2007. Disponible en http://www.voltairenet.org/article 145977.html Consultado el 3 de diciembre de 2009.

Clastres, P. (1973): La sociedad contra el Estado. Caracas: Monte Ávila.

Clastres, P. (1981): Investigaciones de antropología política. Barcelona: Gedisa.

Cohen, B.C. (1963): The Press and Foreign Policy. Princeton: Princeton University.

Cotteret, J. M. [1997] (2002): Gouverner, c'est paraître. París: PUF Quadrige.

DAYAN, D. y KATZ, E. (1995): La historia en directo. La retransmisión televisiva de los acontecimientos. Barcelona: Gili.

DeborD, G. (1976): La sociedad del espectáculo. Barcelona: Anagrama.

Debord, G. (1990): Comentarios a la sociedad del espectáculo. Barcelona: Anagrama.

Debray, R. (1991): Cours de médiologie générale. París: Gallimard.

DomenaCh, J. M. [1950] (1973): La propaganda política. Buenos Aires: Eudeba.

ECO, U. (1986): “TV: La transparencia perdida”, en La estrategia de la ilusión. Buenos Aires: Lumen.

Freud, S. (1982): Tótem y Tabú. Madrid: Alianza.

FREUD, S. (1984): El porvenir de una ilusión. Madrid: Alianza.

FREUD, S. (2006): Malestar en la cultura. Madrid: Alianza.

GAUChET, M. (2000): “Cuando los derechos devienen una politica”, en GAUCHET, M.: La democracia contra si misma. Rosario: Homo Sapiens. 
Gauchet, M. (2006): “Contre pouvoir, meta-pouvoir, anti pouvoir”, Le Débat, $\mathrm{n}^{\circ}$ 138, pp. 17-29.

GARCÉs, R. (2009): “La construcción simbólica de la opinión pública”, en VALQUI, C. Y Pastor, C.: Capital, Poder y Medios de Comunicación: Una Crítica Epistémica. Perú: Universidad Privada Antonio Guillermo Urrelo, pp.115-171.

García Canclini, N. (1989): Culturas Híbridas, Estrategias para entrar y salir de la Modernidad. México: Grijalbo.

García Canclini, N. (2004): Diferentes, desiguales y desconectados. Mapas de la interculturalidad. Barcelona: Gedisa.

GARcía CANClini, N. (2007): Lectores, espectadores e internautas. Barcelona. Gedisa.

Gonzalez Broquen, X. (2007): "El poder simbólico de los medios de comunicación”, Dikaiosyne, vol. 17, pp. 30-38.

GonZALEZ BRoquen, X. (2008): “Identificación versus identidad: del nosotros estético y la alineación simbólica. Variaciones críticas a partir de una lectura de La transfiguración de lo Político de Michel Maffesoli”, en Martínez, X y D’Amario, D. (eds.): Apuntes de políticas, democracias y socialismos en Venezuela. Caracas: CIPOST-FACES-UCV, pp. 153-163.

Gonzalez Broquen, X. (2009): "La dimensión estética del poder mediático", Enl@ce. Revista Venezolana de Información, Tecnología y Conocimiento, no 3, pp. 97104.

HABERMAS, J. (1981): Historia y crítica de la opinión pública. La transformación estructural de la vida pública. Barcelona: Gustavo Gili.

Habermas, J. (1989): "La esfera o el espacio de la opinión pública”, en Facticidad y Validez. Madrid: Trotta, pp. 440-446.

Hall, S. (1973): "Encoding and Decoding in the Media Discourse", Stencilled Paper, n $^{\circ}$ 7, pp. 128-138.

InNIS, H. (1950): Empire and Communications. Toronto: University of Toronto.

InNIS, H. (1951): The Bias of Communication. Toronto: University of Toronto.

Jiménez, D. (2004): La era de la fe ciega: Medios de comunicación y producción de alteridad. Madrid: CAES (Centro de Asesoría y Estudios Sociales). 
Landi, O. (1991): "Videopolítica y Cultura”, Diálogos de la Comunicación, nº 29, pp. 24-35.

LASCH, C. [1975] (1999): La cultura del narcisismo. Santiago de Chile: Andrés Bello.

LaZarsfeld, P. F. y Katz, E. (1955): Personal Influence. New York: Free Press.

Lazarsfeld, P. F., Berelson, B. y Gaudet, H. (1944): The People's Choice: How the Voter Makes Up His Mind in a Presidential Campaign. New York: Duell, Sloan and Pearce.

Liebes, T. y KATZ, E. (1990): Export Of meaning: cross-cultural readings of Dallas. New York: Oxford University.

Lippmann, W. [1922] (1997): Public Opinion. New York: Free Press Paperbacks.

Maffesoli, M. (2005): La transfiguración de lo político. La trivialización del mundo posmoderno. México: Herder.

Marcuse, H. [1954] (1993): El hombre unidimensional. Buenos Aires: PlanetaAgostini.

Martín-Barbero, J. (1987): De los medios a las mediaciones. México: Gustavo Gili.

Martín-BARbero, J. (1998): "Penser la société à partir de la communication", Loisir et Société, vol. 21, n 1, pp. 145-172.

Matterlart, A. (1971): "El medio de comunicación de masas en la lucha de clases”, Pensamiento Crítico, no 53, pp. 4-44.

Mattelart, A. (2009): Histoire de l'utopie planétaire. París: La Découverte.

McCombs, M. (1994): "Influencing the pictures in our heads: two dimensions of Agenda-setting”, Journal of Mass Communication Studies, n 25, pp. 171-181.

McCombs, M. E. y SHAw. D. L. (1972): “The Agenda-Setting Function of Mass media”, Public Opinion Quarterly vol. 36, n 2, pp. 176-187. DOI: 10.1086/267990; http://dx.doi.org/10.1086/267990

McLuhan, M. y Powers, B. R. [1989] (1995): La aldea global. Barcelona: Gedisa. 
NAdeau, R. y BAStien, F. (2003): "La communication électorale", en GingRas, A.M. (dir.) : La communication politique : état des savoirs, enjeux et perspectives. Montréal: Université du Québec, pp. 159-188.

PACKHARD, V. [1957] (1959): Las formas ocultas de la propaganda. Buenos Aires: Sudamericana.

SARTORI, G. (2002): Homo videns: La sociedad teledirigida. Madrid: Taurus.

TARde, G. [1989] (1999): L'Opinion et la Conversation, L'Opinion et la foule. París: PUF.

TAYLOR, C. [1989] (1996): Fuentes del yo: la construcción de la identidad moderna. Barcelona: Paidós.

TChakhotine, S. (1939): Le viol de foules par la propagande politique. París: Gallimard.

VAneigem, R. (1967): Traite de savoir vivre a l'usage des juenes generations. Paris: Gallimard.

Virilio, P. (2007): Ciudad Pánico. El afuera comienza aquí. Caracas: Monte Ávila.

VIRILIO, P. (1999): La bomba informática. Madrid: Cátedra.

Wolton, D. (1992): Elogio del gran público. Una teoría critica de la televisión. Barcelona: Gedisa.

Wolton, D. (1998): "Las contradicciones de la comunicación política”, en GaUthier, Gilles et al:: Comunicación y política. Barcelona: Gedisa, pp. 110-130. 


\section{PARA CITAR ESTE TRABAJO EN BIBLIOGRAFÍAS:}

GONZÁLEZ BROQUEN, Ximena (2011): "Hacia una categorización del poder mediático: poder representativo, meta-poder y anti-poder", Mediaciones Sociales. Revista de Ciencias Sociales y de la Comunicación, $\mathrm{n}^{\mathrm{o}}$ 8, pp. 47-68. DOI: 10.5209/rev_MESO.2011.n8.3; http://dx.doi.org/10.5209/rev_MESO.2011.n8.3

\section{${ }^{(*)}$ La autora}

Ximena González Broquen es doctora en Estudios Políticos y Filosofía por la Escuela de Altos Estudios en Ciencias Sociales (EHESS) de Francia y está especializada en temas relativos a comunicación y poder. Actualmente desarrolla un proyecto de investigación sobre el papel de las TIC en el desarrollo de la democracia participativa y protagónica en Venezuela en el Centro de Estudio de la Ciencia del Instituto Venezolano de Investigaciones Científicas (IVIC), donde se desempeña como investigadora y Jefa de Centro de Estudio de la Ciencia. Estudios: Post-doctorado en el Centro de Investigaciones Postdoctorales (Cipost-Faces) de la Universidad Central de Venezuela (UCV); Doctorado y Master (DEA) de Estudios Políticos y Filosofía, por la Escuela de Altos Estudios en Ciencias Sociales (EHESS), París, Francia; Licenciatura de Filosofía, por la Universidad Sorbona (París 1, Panteón Sorbonne).

RECIBIDO: 26 de enero de 2011.

ACEPTADO: 10 de junio de 2011. 